\title{
Alopecia totalis
}

INSERM

\section{Source}

INSERM. (1999). Orphanet: an online rare disease and orphan drug data base. Alopecia totalis. ORPHA:700

Alopecia totalis is a form of alopecia areata, an inflammatory disease of the hair follicle, characterized by a complete loss of hair of the entire scalp which becomes glabrous. 